\title{
NUMERICAL INVESTIGATION OF COOLING A RIBBED MICROCHANNEL USING NANOFLUID
}

\author{
Khadija Madani1,*, Rejeb Ben Maad ${ }^{1}$, Aissa Abidi-Saad ${ }^{2}$
}

\begin{abstract}
A 2-D numerical investigation was carried out to study the effect of spacing between ribs on nanofluid flow and heat transfer inside a horizontal micro-channel. Two identical ribs were placed at the lower wall of micro-channel with variable spacing between them. The alumina oxide nanoparticles was suspended in water as based fluid at different volume fraction 0,2 and $4 \%$. The finite volume method was used to solve the continuity, momentum and energy equations. The effects of different parameters such as nanoparticles volume fraction, Reynolds number, and the spacing between ribs has been evaluated. The results showed that increasing nanoparticles volume fraction and Reynolds number significantly enhanced the heat transfer and the Poiseuille number. The presence of ribs improves the heat transfer. However, increasing the spacing between ribs leads to decrease the heat transfer rate.
\end{abstract}

\section{Keywords: Forced Convection, Heat Transfer Coefficient, Nanofluids, Ribs}

\section{INTRODUCTION}

The application of convective heat transfer is widely developed in numerous fields, such as, cooling system of electronic equipment, compact heat exchangers and cooling nuclear reactors. However, the convective heat transfer process failed to provide sufficiently the highest heat transfer enhancement requested. Therefore, improving its tools becomes a mandatory challenge. Thus, enhancing convective heat transfer can be reachedby the passive or the active method [1]. The passive technique consists on modifying the flow geometry, boundary conditions or enhancing thermal conductivity of the fluid. Reduce the flow geometry could be primordial solution to lessen loss energy and raise heat transfer.In this area, it was affirmed the significant advantages of using micro-channel in energy conservation and electronic equipment cooling. Tuckerman and Pease [2] were the pioneer who studied the heat transfer in micro-channel. They found that using micro-channel with $50 \mu \mathrm{m}$ width and $302 \mu \mathrm{m}$ of depth could efficiency remove the high heat transfer rate of $800 \mathrm{w} / \mathrm{cm}^{2}$.Due to its large applications, research has been focused to improve the heat transfer mechanism in micro-channel. This enhancement could be achieved by improving fluid proprieties because the usual worked fluid has a poor thermal conductivity. Thus, it failed to provide sufficiently the highest heat transfer enhancement asked. For this reason, developing a new heat transfer fluid becomes a challenge to overcome this impediment. Suspending solid particles with diameter less than $100 \mathrm{~nm}$ enhanced the thermal conductivity of fluidchoi [2]. On account of the huge benefits of using nanofluid, numerous researchers have focused on studying the nanofluid effective thermal conductivity. Mainly, the studies (Yoo et al. [4], Choi et al. [5]) affirmed that the measured thermal conductivity of nanofluid was higher compared to the classic theoretical predictions (Hamilton and Crosser, 1962 [6]). Experimentally, Masuda et al [7] found that the effective thermal conductivity of nanofluid increases as nanoparticles volume fraction increase. Due to the advantage of increasing thermal conductivity, measureless works focused on studying the nanofluid flow and the heat transfer. Otherwise, many researchers have proved that using rough surface could be a powerful technique to height en convective heat transfer rate. Danish et al. [8] has highlighted that employing ribbed surface increases the convective heat transfer. Thereafter, numerous experimental and numerical investigations have explored the impact of using nanofluid as worked fluid in ribbed micro-channel. Laminar nanofluid flow and forced convection in ribbed micro-channel has been reported by Yari Ghale et al [9]. They found that the presence of ribs in the surface of microchannel led to increase the Nusslet

This paper was recommended for publication in revised form by Regional Editor Ahmed Kadhim Hussein

${ }^{1}$ Laboratoire d'Énergétique et des Transferts Thermique et Massique LETTM, Faculté des Sciences de Tunis, Université de Tunis El Manar.

${ }^{2}$ University Kasdi Merbah-Ouargla, 30000, Algeria

*E-mail address: khadijamadani88@gmail.com

Manuscript Received 17 June 2017, Accepted 25 October 2017 
number and the friction factor. Hunh et al [10] has conducted an experimental investigation to evaluate the impact of tooth height on heat transfer in rectangular channels. Their study revealed that increasing the blockage ratio enhanced the convective heat transfer. Akbari et al [11] have numerically investigated the nanofluid flow and heat transfer in micro channel. It was found that the heat transfer rate, the friction coefficient and the average Nusselt number increase with increasing nanoparticles volume fraction and ribs heights. Karimipour [12] conducted a numerical study on nanofluid forced convection in microchannel. It was showed that increasing the Reynolds number and nanopartilces volume fraction enhances the heat transfer rate. Also, they concluded that the presence of ribs significantly affects of dimensionless temperature and velocity. Al-Shamani et al. [13] have numerically investigated nanofluid turbulent flow and heat transfer trough ribbed-grooved channel. Nanoparticles of $\mathrm{Al}_{2} \mathrm{O}_{3}, \mathrm{CuO}$ and $\mathrm{SiO}_{2}$ were dispersed in water as based fluid at different volume fraction. The finding showed that trapezoidal rib-groove using nanofluid significantly enhances the heat transfer. Turbulent flow ad heat transfer in two dimensional ribbed channel was investigated by Manca et al [14] nanoparticles of $\mathrm{Al}_{2} \mathrm{O}_{3}$ were dispersed in water. The results showed that the heat transfer enhancement increases with volume fraction and Reynolds number increase. Wang et Sunden [15] experimentally studied the shape impact on heat transfer and friction characteristics in a square roughened duct. They have highlighted that ribs shape strongly affect the local heat transfer. It was concluded that the trapezoidal shaped ribs provide the highest heat transfer enhancement. Numerical study of nanofluid forced convection flow in triangular ribbed microchannel has been carried out by Andreozzi et al [16]. They have exanimated the effect of ribs shapes on heat transfer. They found that the rectangular-trapezoidal rib shape provides the highest heat transfer enhancement.

The employment of ribbed micro-channel is widely developed. Nevertheless, few works have been interested to investigate nanofluid flow in ribbed micro channel. Different parameters related to enhancement heat transfer in ribbed micro-channel need to be more understood such as the effect of nanoparticles volume fraction and the spacing between ribs. Understanding the impact of these parameters could allow optimizing the micro-devices design. This was the main motivator for the present work. The current investigation attempted to numerically studied nanofluid laminar flow and heat transfer in ribbed rectangular micro-channel. The nanofluid used in this work consists on dispersing spherical alumina nanoparticles in water for different volume fractions $0-4 \%$. The effect of spacing between the ribs is evaluated.

\section{PHYSICAL MODEL AND MATHEMATICAL FORMULATION}

The configuration analyzed in this study was presented in Fig 1. The micro-channel studied by Akbrai et al [11] has been adopted as based configuration. It consists of a horizontal rectangular microchannel with a length $\mathrm{L}=0.025 \mathrm{~m}$ and height $\mathrm{ofH}=25 \mu \mathrm{m}$. The middle part of the lower wall is maintained at constant temperature $\mathrm{T}_{\mathrm{c}}=293 \mathrm{~K}$ and the rest was adiabatic. Two identical ribs with equal length $\mathrm{a}=\mathrm{L} / 7$ were placed in the lower wall. The first rib was fixed at $x=2 a$ from the entrance of the channel and the second one was movable. Different spacing (b) between the ribs was examined (see Tabe1). Aluminum oxide nanoparticles were dispersed in water at different volume fraction of $0 \%, 2 \%$ and $4 \%$. The nanofluid flow is assumed to be Newtonian, incompressible and laminar $(\mathrm{Re}=10$ and $\mathrm{Re}=100)$ and hydro-dynamically fully developed with average inlet velocity $U_{o}$; and with constant temperature $T_{h}=303 \mathrm{~K}$.

L

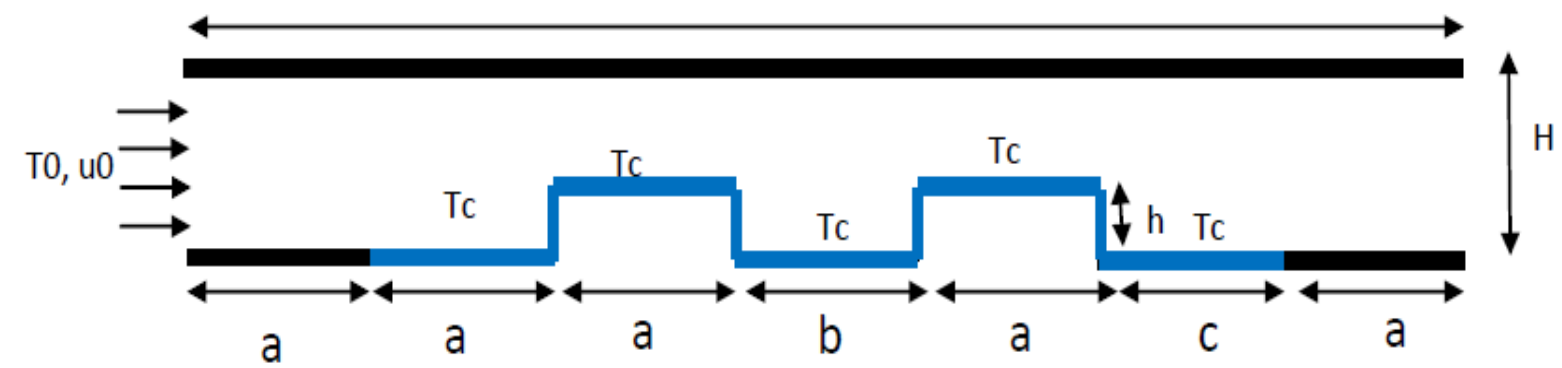

Figure 1. Schematic of investigated microchannel 
Table 1. Studied cases of spacing between ribs

\begin{tabular}{|l|l|l|l|l|l|l|l|l|}
\hline case & A & B & C & D & E & F & G & H \\
\hline $\mathbf{b}$ & $a / 4$ & $2 a / 4$ & $3 a / 4$ & $a$ & $5 a / 4$ & $6 a / 4$ & $7 a / 4$ & $2 a$ \\
\hline c & $7 a / 4$ & $6 a / 4$ & $5 a / 4$ & $a$ & $a / 4$ & $3 a / 4$ & $2 a / 4$ & 0 \\
\hline
\end{tabular}

The single-phase model is used to describe the heat transfer characteristics of nanofluids through a micro channel under cooling condition. The following equations present the mathematical formulation of the singlephase model and two-dimensional [11]:

$$
\begin{gathered}
\frac{\partial U}{\partial X}+\frac{\partial V}{\partial Y}=0 \\
U \frac{\partial U}{\partial X}+V \frac{\partial U}{\partial Y}=-\frac{\partial P}{\partial X}+\frac{\mu_{n f}}{\rho_{n f} v_{f}} \frac{1}{R e}\left(\frac{\partial^{2} U}{\partial X^{2}}+\frac{\partial^{2} U}{\partial Y^{2}}\right) \\
U \frac{\partial V}{\partial X}+V \frac{\partial V}{\partial Y}=-\frac{\partial P}{\partial X}+\frac{\mu_{n f}}{\rho_{n f} v_{f}} \frac{1}{R e}\left(\frac{\partial^{2} U}{\partial X^{2}}+\frac{\partial^{2} U}{\partial Y^{2}}\right) \\
U \frac{\partial \theta}{\partial X}+V \frac{\partial \theta}{\partial Y}=\frac{\alpha_{n f}}{\alpha_{f}} \frac{1}{\operatorname{PrRe}}\left(\frac{\partial^{2} \theta}{\partial X^{2}}+\frac{\partial^{2} \theta}{\partial Y^{2}}\right)
\end{gathered}
$$

In the above equations, following dimensionless parameters are used $X=\frac{x}{H} Y=\frac{y}{H} ; U=\frac{u}{u_{0}} ; V=\frac{v}{v_{0}} ; \operatorname{Pr}=\frac{v_{f}}{\alpha_{f}} ; H=\frac{H}{H}=1 ; \theta=\frac{T-T_{C}}{T_{h}-T_{C}} \operatorname{Re}=\frac{u_{0} H}{v_{f}} ;$

To calculate the local Nusselt number within the ribs width, we use the following equation:

$$
N u(Y)=-\frac{k_{e f f}}{k_{f}}\left(\frac{\partial \theta}{\partial X}\right)_{X=0}
$$

To calculate the local friction factor along the lower wall, the following relation is used:

$$
c_{f}=\frac{\rho_{f} \frac{\partial u}{\partial u}}{\frac{1}{2} \rho_{f} u_{c}^{2}}
$$

\section{PHYSICAL PROPRIETIES OF NANOFLUID}

Nanofluid density is obtained by measuring the volume and weight of the mixture, through the following equation [17]:

$$
\rho_{n f}=(1-\varphi) \rho_{f}+\varphi \rho_{p}
$$

The specific heat is estimated from the correlation proposed by Xuan and Roetzel [19].

$$
\left(C_{p} \rho\right)_{n f}=(1-\varphi)\left(C_{p} \rho\right)_{f}+\left(\varphi C_{p} \rho\right)_{p}
$$


To calculate the effective thermal conductivity of nanofluid for suspensions with spherical particles, Mintsa et al $[17,18]$ correlation is used:

$$
K_{n f}=K_{f}(1.72 \varphi+1)
$$

The effective dynamic viscosity of nanofluid is also measured using the correlation proposed by Maïga et al. [19].

$$
\mu_{n f}=\mu_{b f}\left(123 \varphi^{2}+7.3 \varphi+1\right)
$$

The physical properties of the based fluid and aluminum oxide used in the simulation are shown in Table 2.

Table 2. Properties of base fluid (water) and nanoparticles.

\begin{tabular}{|l|c|c|c|c|}
\hline & $\rho(\mathbf{k g} / \mathbf{m 3})$ & $\mathbf{C p}(\mathbf{J} / \mathbf{k g K})$ & $\mathbf{K}(\mathbf{W} / \mathbf{m K})$ & $\boldsymbol{\mu}(\mathbf{k g} / \mathbf{m s})$ \\
\hline Water & 998.2 & 4182 & 0.6 & $9.93 \times 10^{-4}$ \\
\hline $\mathbf{A l}_{2} \mathbf{O}_{3}$ & 3880 & 733 & 36 & \\
\hline
\end{tabular}

\section{NUMERICAL METHED AND GRID INDEPENDENCE TEST}

The governing equations of mass, momentum and energy (1) - (4) are solved numerically using the finite volume method based code (Ansys Fluent). In the solver configuration, the pressure-based solver was used that can solve sequentially transport equations. The coupling between velocity and pressure is achieved with the SIMPLEC algorithm that solves the equations of continuity and momentum simultaneously and gives an advantage to treat flows with a strong interdependence between dynamic and thermal fields. Second-Order Upwind Schemes and second order central difference are used for the spatial discretization for convective terms and diffusive terms respectively. The convergence criteria were based on the absolute residuals resulting from the integration of the conservation equations over finite control volumes. For all simulations performed in this study, converged solutions were achieved after a residual decrease larger than $10^{-6}$ for all the governing equations

The microchannel is covered with a uniform grid with a special refinement to take care of the phenomena in the vicinity of the walls. To evaluate the influence of grid dimension on the precision of the predicted results, a grid independence tests were performed for fluid flow through a microchannel with rectangular ribs. Water $(\varphi=0 \%)$ was the working fluid and $b=a$ was the adopted case. Six different grid arrangements have been tested (31,000 cells, 37,200 cells, 46,500 cells, 55,800 cells, 62,000 cells and 72,900 cells), see Table 3 . The results showed that after 55,800 cells, the difference between results is less than $0.5 \%$. Therefore, this grid number was adopted for all simulation because it promotes the accuracy requirements and reduces the computational time.

Table 3. Grid independence study for $\operatorname{Re}=10, \phi=0.00$ in case $b=a$.

\begin{tabular}{|c|r|r|r|r|r|r|}
\hline Grids & $\mathbf{3 1 0 0 0}$ & $\mathbf{3 7 2 0 0}$ & $\mathbf{4 6 5 0 0}$ & $\mathbf{5 5 8 0 0}$ & $\mathbf{6 2 0 0 0}$ & $\mathbf{7 2 9 0 0}$ \\
\hline $\boldsymbol{N} \boldsymbol{u}_{\boldsymbol{m}}$ & 5,29412703 & 5,30851931 & 5,32302632 & 5,33279964 & 5,33772038 & 5,34274275 \\
\hline $\boldsymbol{c}_{\boldsymbol{f}_{\boldsymbol{m}}}$ & 10,9680721 & 10,9826718 & 10,9932395 & 10,9998726 & 11,0026369 & 11,0070265 \\
\hline
\end{tabular}

\section{VALIDATION}

In order to ascertain the reliability and precision of the numerical methods and the parameter setting in the used code, the simulation results were compared with those carried out by [11]. Fig 2 and 3 depicts a comparison between their results and the current simulation results for dimensionless temperature and velocity 


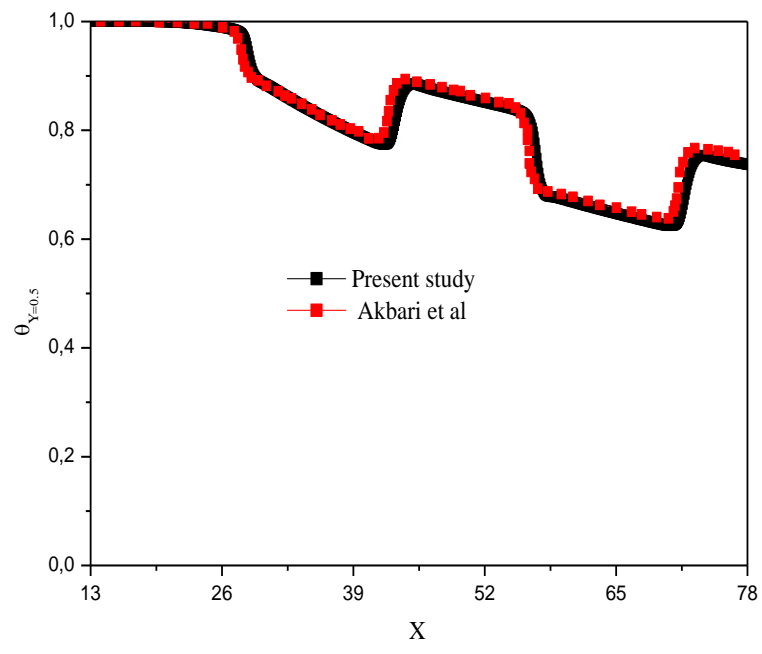

Figure 2. Dimensionless temperature profiles at the center line of microchannel for $\mathrm{Re}=$ 100

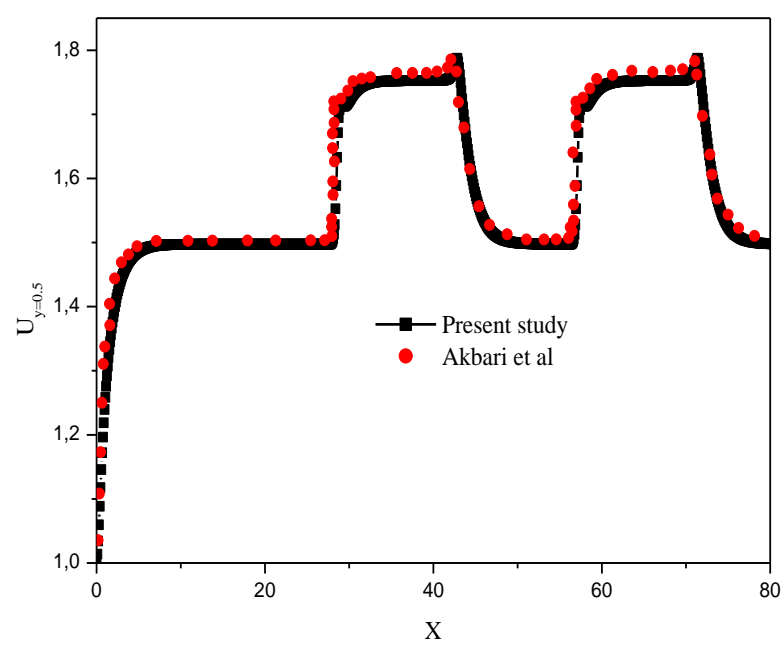

Figure 3. Dimensionless velocity profiles at center line of microchannel for $\mathrm{Re}=100$

profiles at center line of micro-channel for $\mathrm{Re}=100$. It is clearly seen that there is a good corresponding between both results within 5\% margin. Hence, the model could be used for heat transfer calculation with reasonable accuracy.

\section{RESULTS}

The present investigation was carried out using $\mathrm{Al}_{2} \mathrm{O}_{3}$-water nanofluid, with nanoparticles volume fraction of $0,2 \%$ and $4 \%$. The results focused on the effect of volume fraction of nanoparticles, Reynolds number and spacing between ribs on fluid flow and heat transfer in micro channel.

To exanimate the effect of distance between ribs on flow structures in the micro-channel, velocity contours and streamlines are presented in figure 4 (a) and (b) respectively. As can be see, the fluid flow is fully developed in the entrance area. Getting closer the ribs, the flow development was perturbed and the velocity increases. This increasing is due to the presence of ribs which reduces the cross section of flow. With increasing the spacing between ribs, the hot fluid has more time to mix with the cooled fluid which explains the diminution of fluid temperature.

Figure 5 depicts the isotherms within the micro-channel for different ribs spacing. As seen from the figure 5, the fluid enters with hot temperature and it decreases with reaching the cold zone. Increasing the spacing between ribs led to reduce the fluid temperature. The main reason behind this decreasing is that the large spacing between ribs facilitates tothe fluid to be in contact with cold zone for more time and improves the mixing between the hot and cold fluid.

Figure 6 depicts the effect of nanoparticles volume fractions and Reynolds numbers on the dimensionless temperature profiles at $\mathrm{Y}=0.5$. From the figures, it is observed that the dimensionless temperatures oscillate periodically with the presence of ribs. The profiles showed that the dimensionless temperature rapidly decreases from the maximum value noted at $\mathrm{X}=0$, and reaches its minimum at the outlet of micro-channel. Thus, for $\mathrm{Re}=100$, the minimum temperature values were noted at ribs surfaces. For all the cases, the dimensionless temperature deceases with increasing nanoparticle volume fraction. The main reason behind this improve is that adding nanoparticles in based fluid changes the thermo-physic proprieties of fluid mainly and it increases the thermal conductivity which improves the energy exchange process between the fluid and microchannel wall. The effect of Reynolds number has been studied. In fact, increasing the Reynolds number could be occurs by intensified the inlet velocity of the nanofluid. This increasing in velocity contributed to intensify the heat transfer which can be the reason of increasing the nanofluid temperature. Furthermore, considering that the Reynolds number is the ratio of inertial forces to viscosity forces, with constant volume fraction of the nanoparticles and thus constant viscosity forces. So, increasing or decreasing Re increases or decreases the inertial forces. 


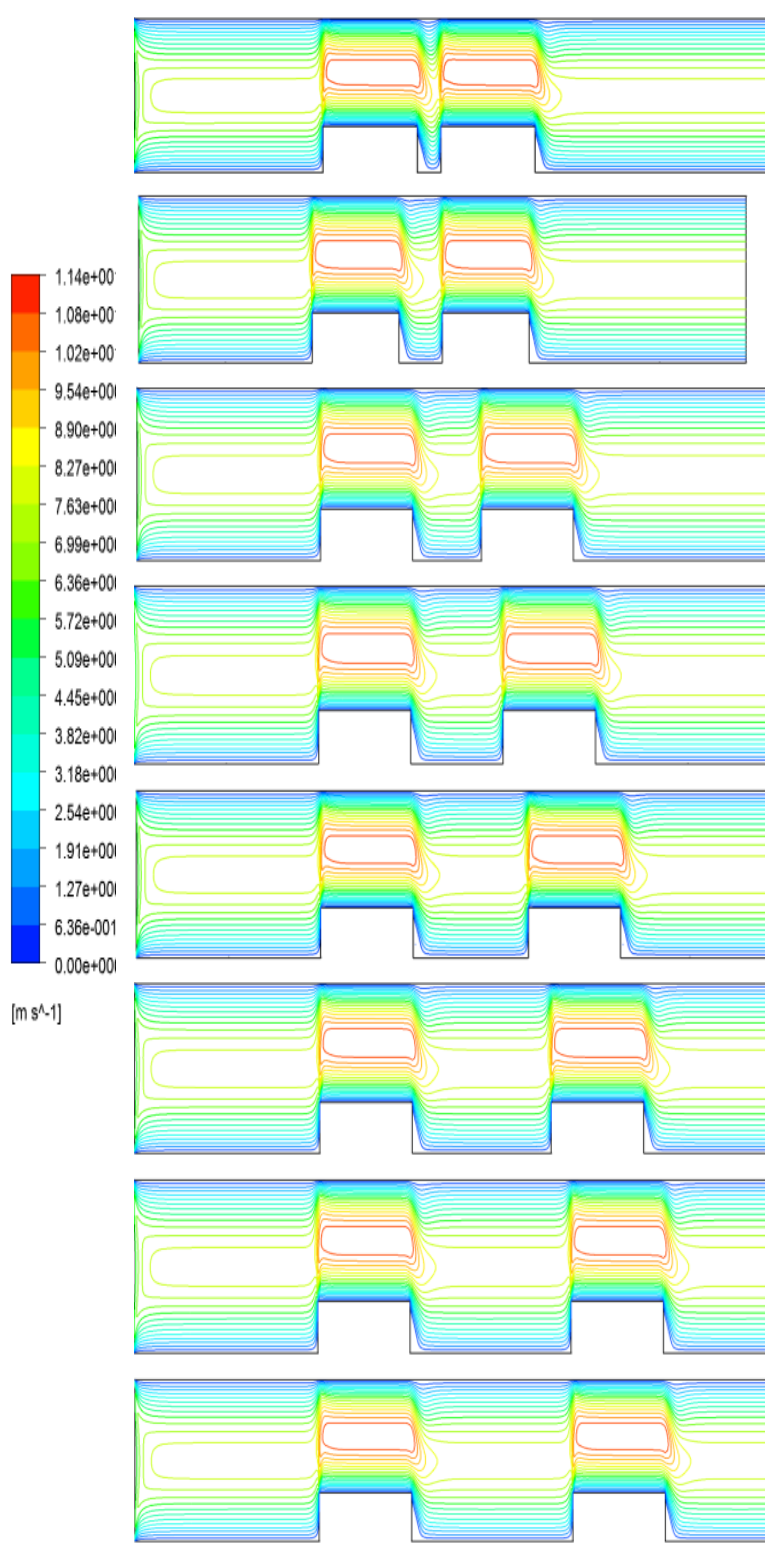

Figure 4(a). Velocity contours for $\varphi=4 \%$ and $\mathrm{Re}=100$

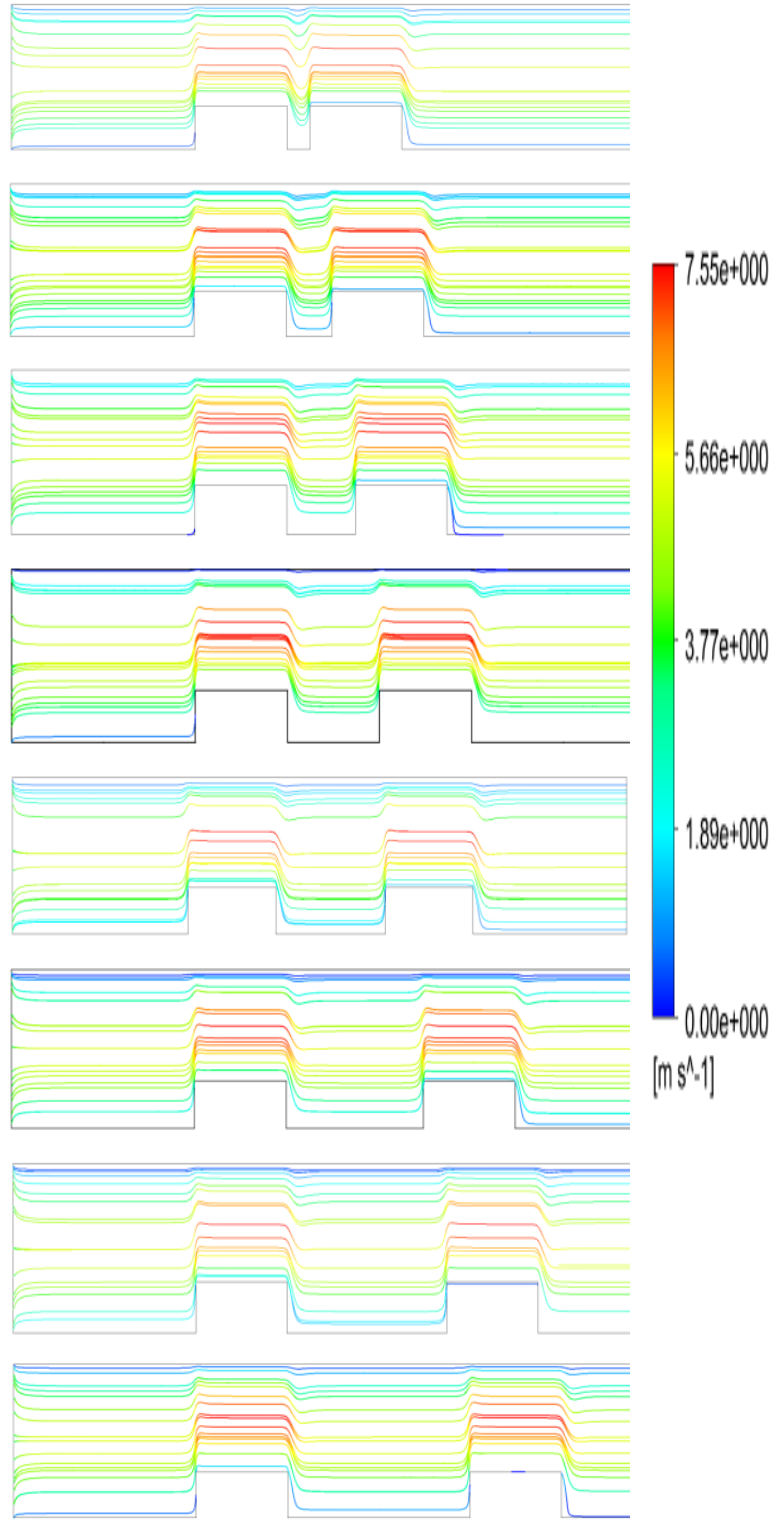

Figure 4(b). Streamlines for $\varphi=4 \%$ and $\mathrm{Re}=100$

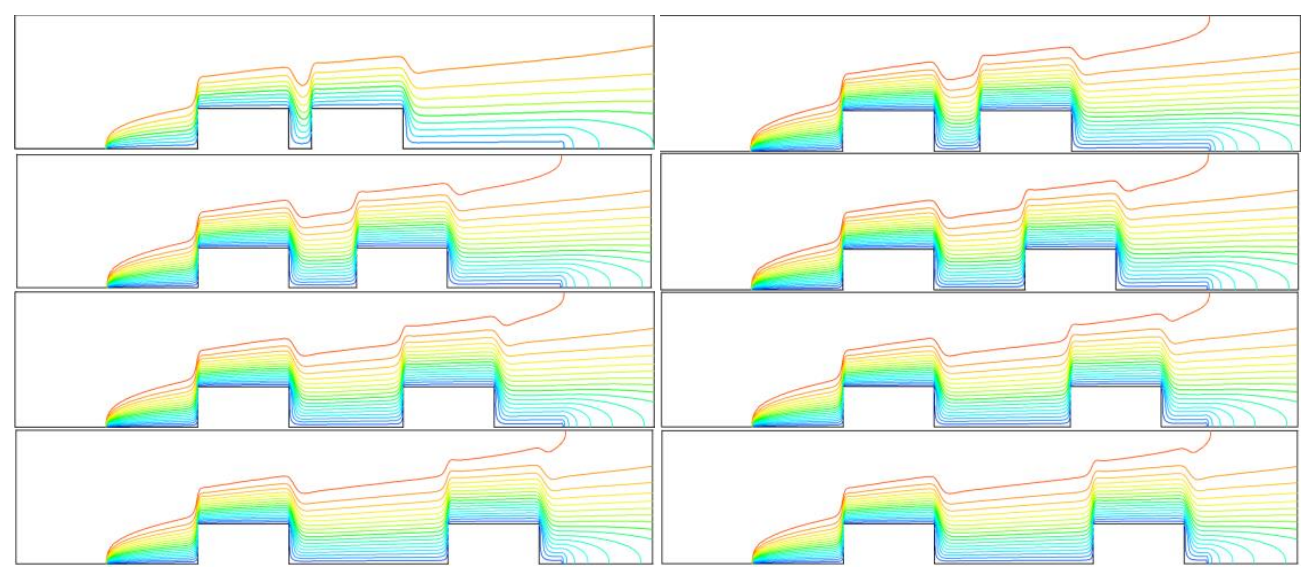

Figure 5. Isotherms for $\varphi=4 \%$ and $\operatorname{Re}=100$ 

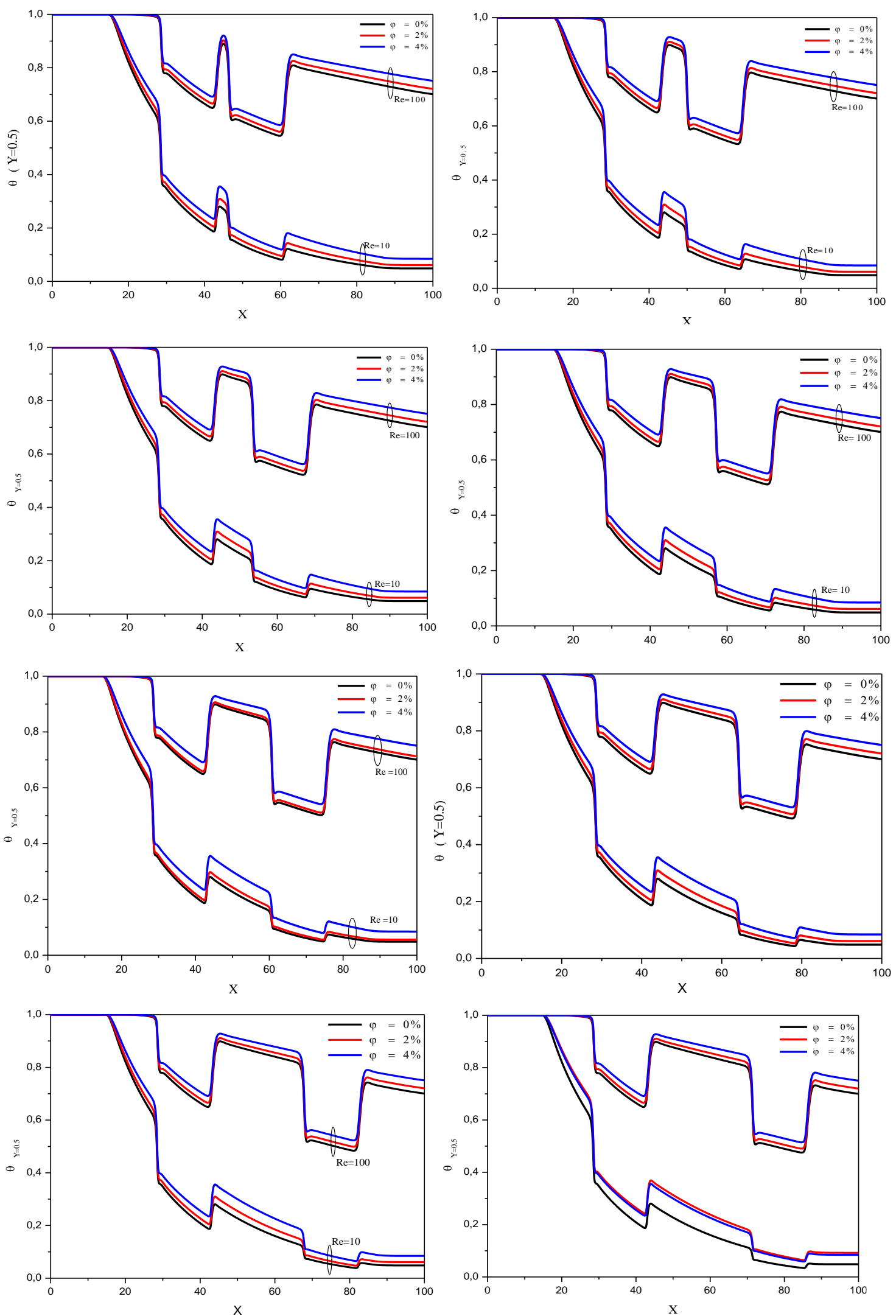

Figure 6. Dimensionless temperature profiles at center line of microchannel for different volume fraction. 


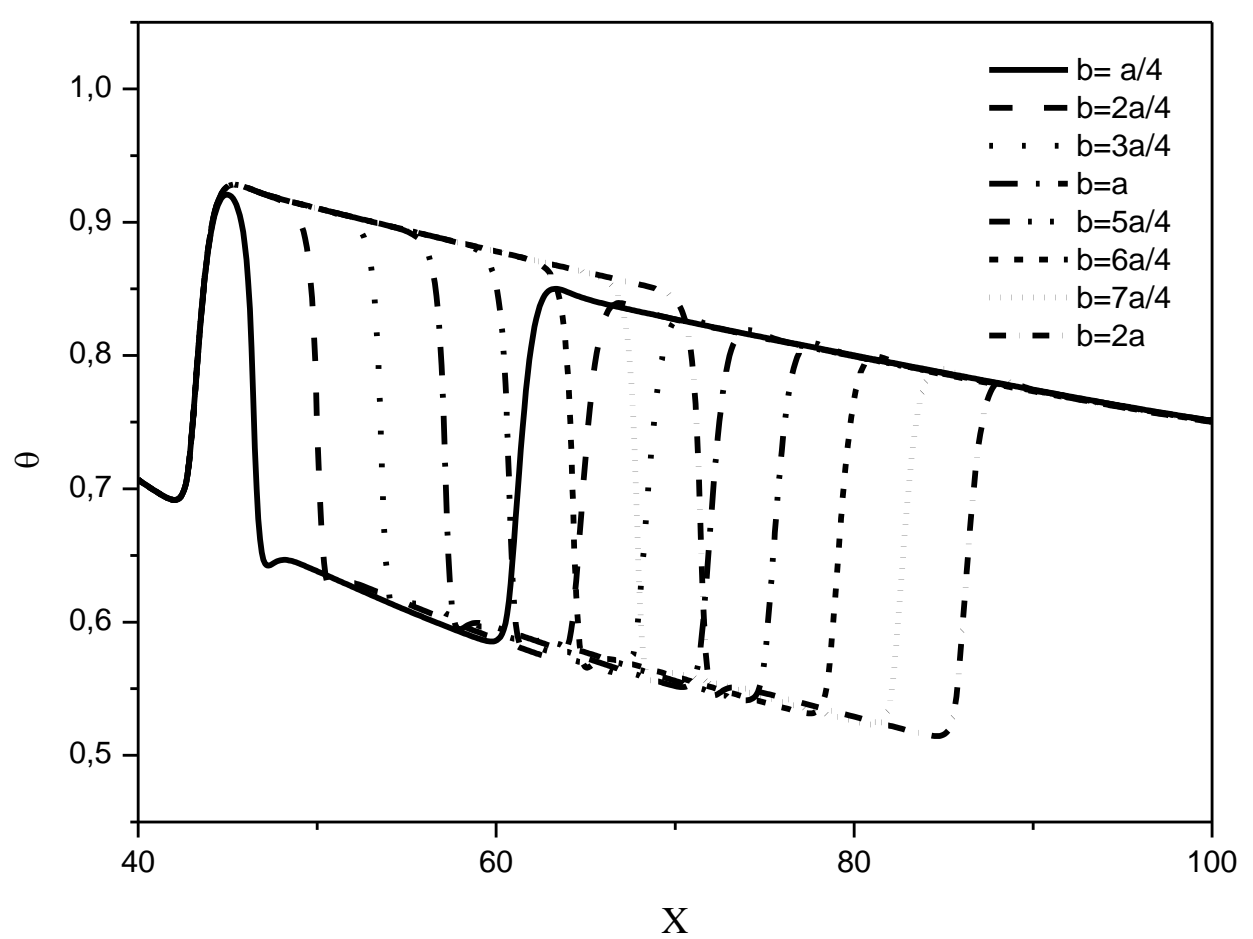

Figure 7. Effect of spacing between ribs on temperature for $4 \%$ and $\mathrm{Re}=100$.

The effect of spacing between the ribs on dimensionless temperature at the center of micro-channel is illustrated in figure7. It is found that increasing the distance that separates the ribs decreases the temperature under this section. This is due to the fact that increasing the ribs spacing promotes the heat exchange between the hot fluid and the cold surface

Figure 8 presents the profiles of the axial dimensionless velocity of nanofluid for $\varphi=4 \%$ at different Reynolds number 10 and 100. It is clearly seen that the nanofluid flow is developed after overshoot the entrance zone $X=7.22$. The profiles indicate the presence of a peak of velocity at the corners of the ribs which is related to the adhesion condition. When reaching the ribs, the dimensionless velocity increases sharply. This is can be explained by the fact that the presence of the ribs in micro-channel reduces the cross section of nanofluid flow.

It is found that flow is quickly fully developed for lower Reynolds number $\mathrm{Re}=10$ compared to higher value of $\mathrm{Re}=100$. Figure 9 displayed the effect of increasing spacing between ribs on dimensionless velocity for $4 \%$ nanoparticle volume fraction and at Reynolds number of 100 . The velocity decreases after crossing the first rib surface. Thereafter, it increases again when the fluid enters on contact with the second ribs. It is noted that growing the space between ribs decreases the nanofluid velocity. And the fluid is fully developed for greater value of $b$.

Figure10 displayed the local Nusselt number on the lower wall of the microchannel for different volume fraction of nanoparticles in based fluid for all the cases and for Reynolds number of 100. The results show that increasing nanoparticles volume fraction and Reynolds number improve Nusselt number of nanofluid. This enhancement could be due to the fact that adding nanoparticles with different volume fraction affects the physical proprieties of the mixture. Thus, nanofluid thermal conductivity was higher than those for based water which intensifies the heat transfer. Furthermore, heat transfer enhancement can be explaining by the fact that increasing the nanoparticle volume fraction leads to intensity the interactions and the collisions between nanoparticles and walls and thus cause a higher heat transfer and Nusselt number. Ribs are another factor that increases the Nusselt number. This increment is related to the fact that the presence of ribs interrupts the thermal boundary layer development which contributes to enhance the heat transfer rate. The effect of increasing ribs spacing between ribs on Nusselt number is presented in Fig 11. It is found that when the space between ribs increases the Nusselt number decreases. 
Journal of Thermal Engineering, Research Article, Vol. 4, No. 6, pp. 2408-2422, October, 2018
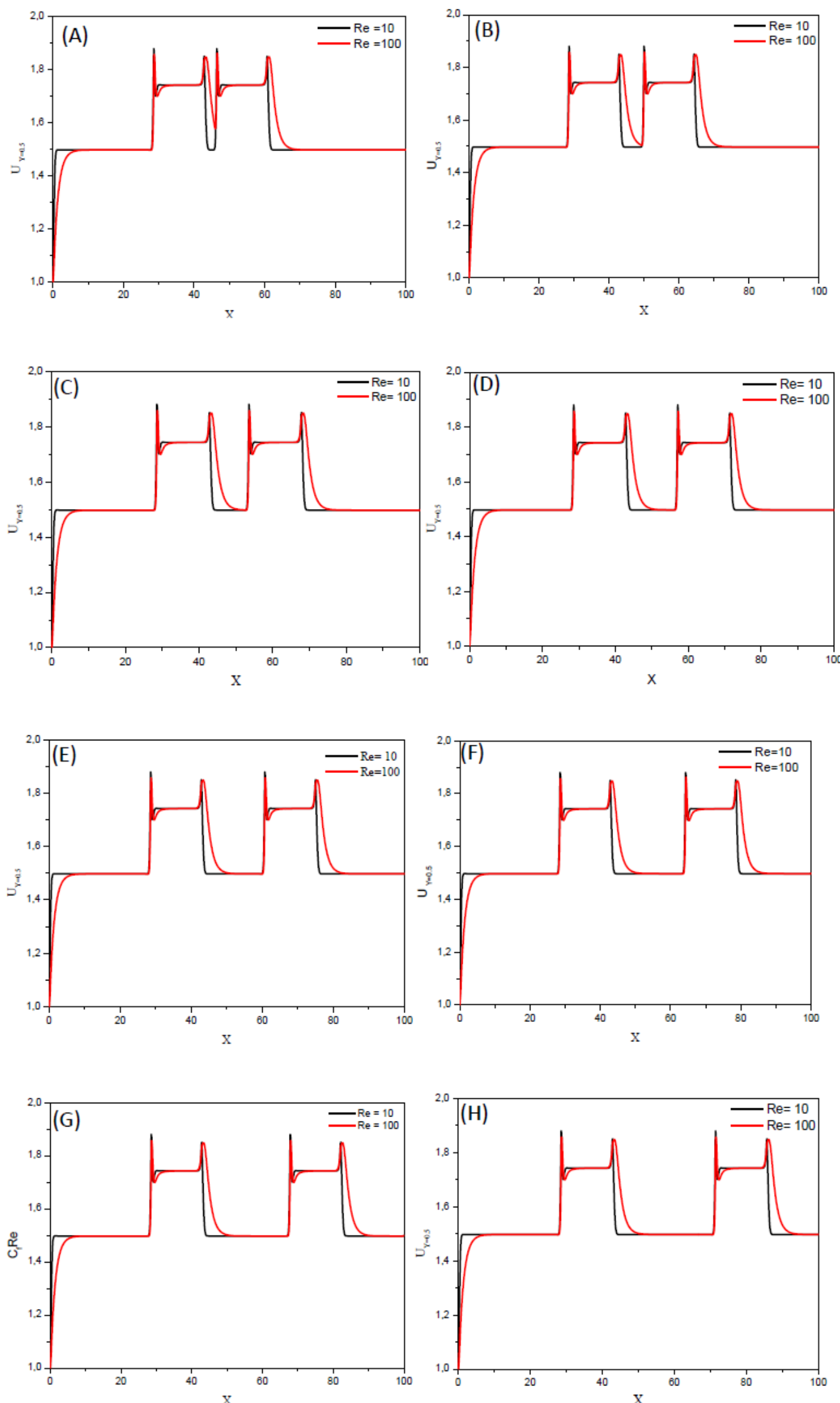

Figure 8. Dimensionless velocity profiles at center line of micro-channel for Reynolds numbers of 10 and 100. 


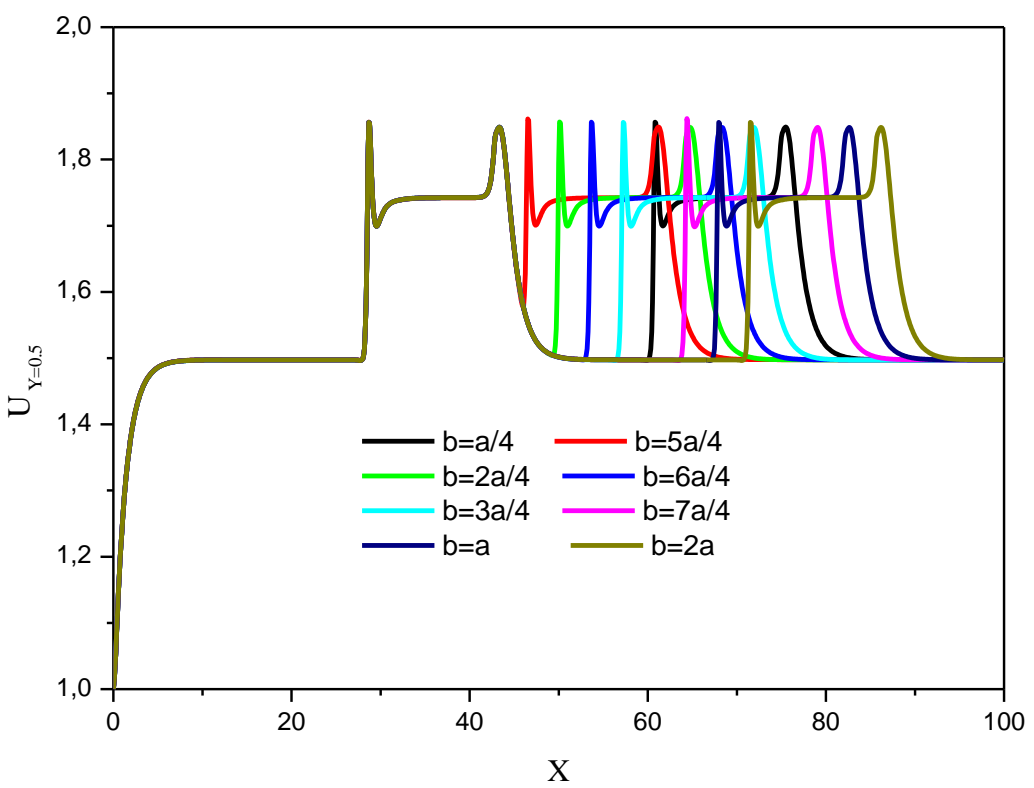

Figure 9. Effect of spacing between ribs on dimensionless velocity profiles at center line of micro-channel for
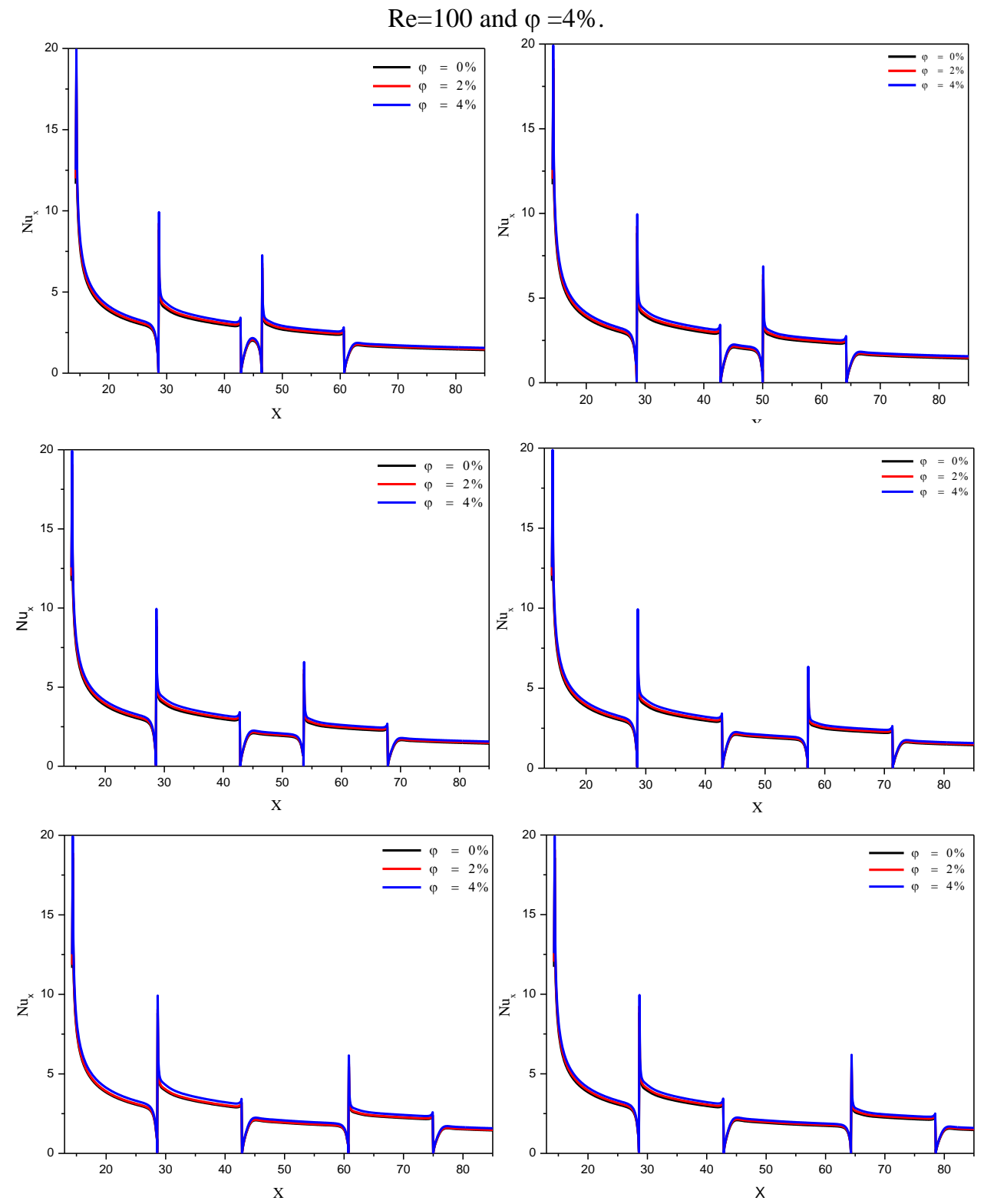

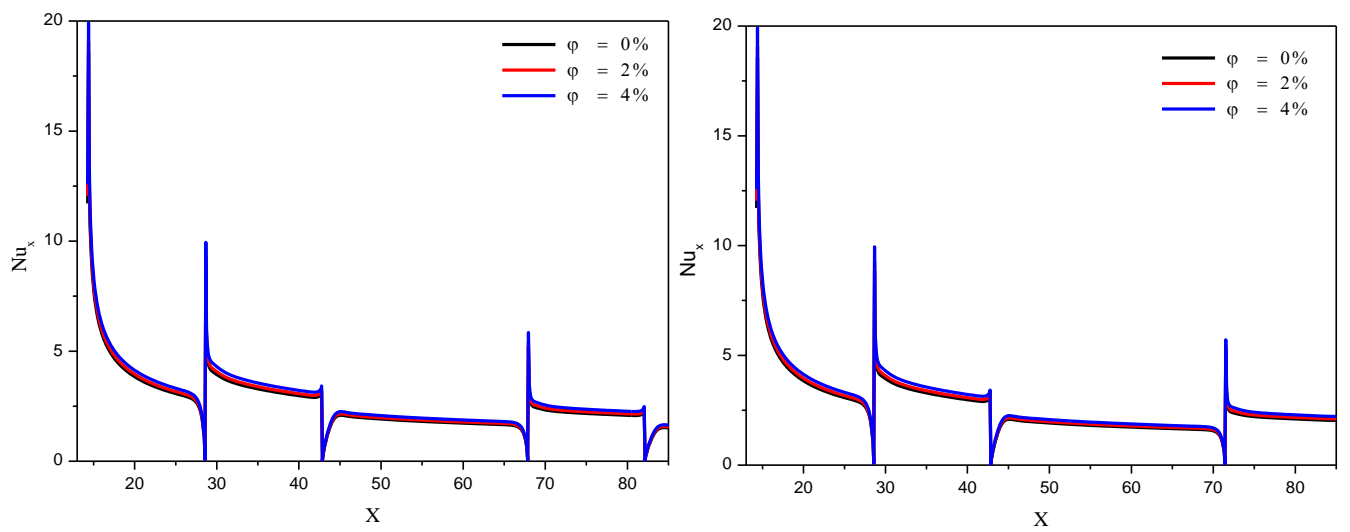

Figure 10. Local Nusselt number on lower rib-roughened wall for $\mathrm{Re}=100$.

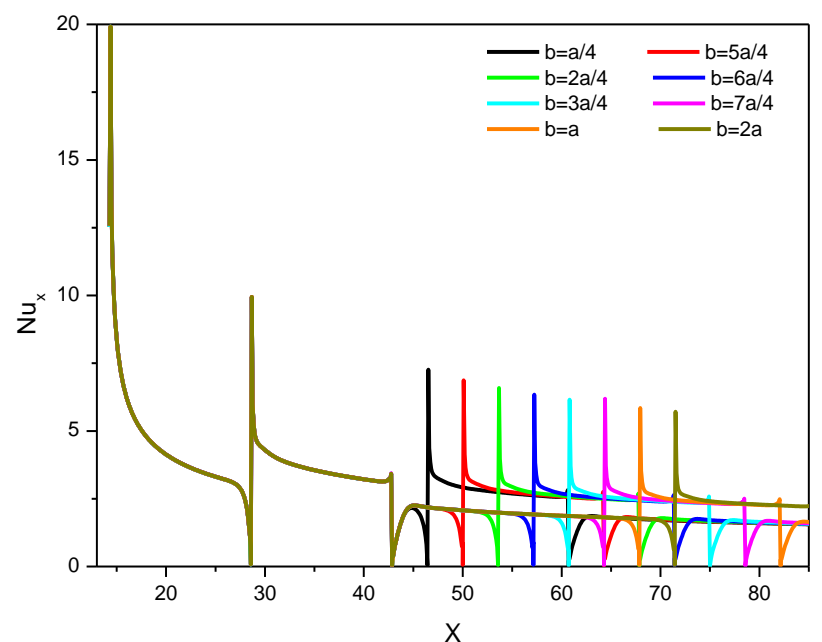

Figure 11. Effect of spacing between ribs on Local Nusselt number for $\varphi=4 \%$ and at $\operatorname{Re}=100$.

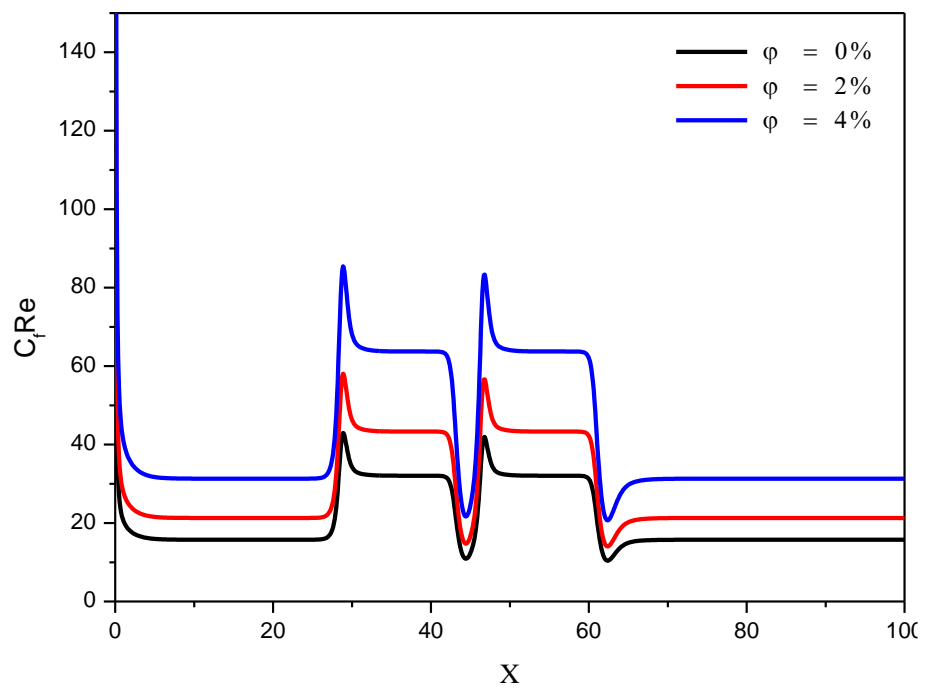

Figure 12. Effect of volume fraction on Poiseuille number along the upper wall of micro-channel for $\operatorname{Re}=100$. 

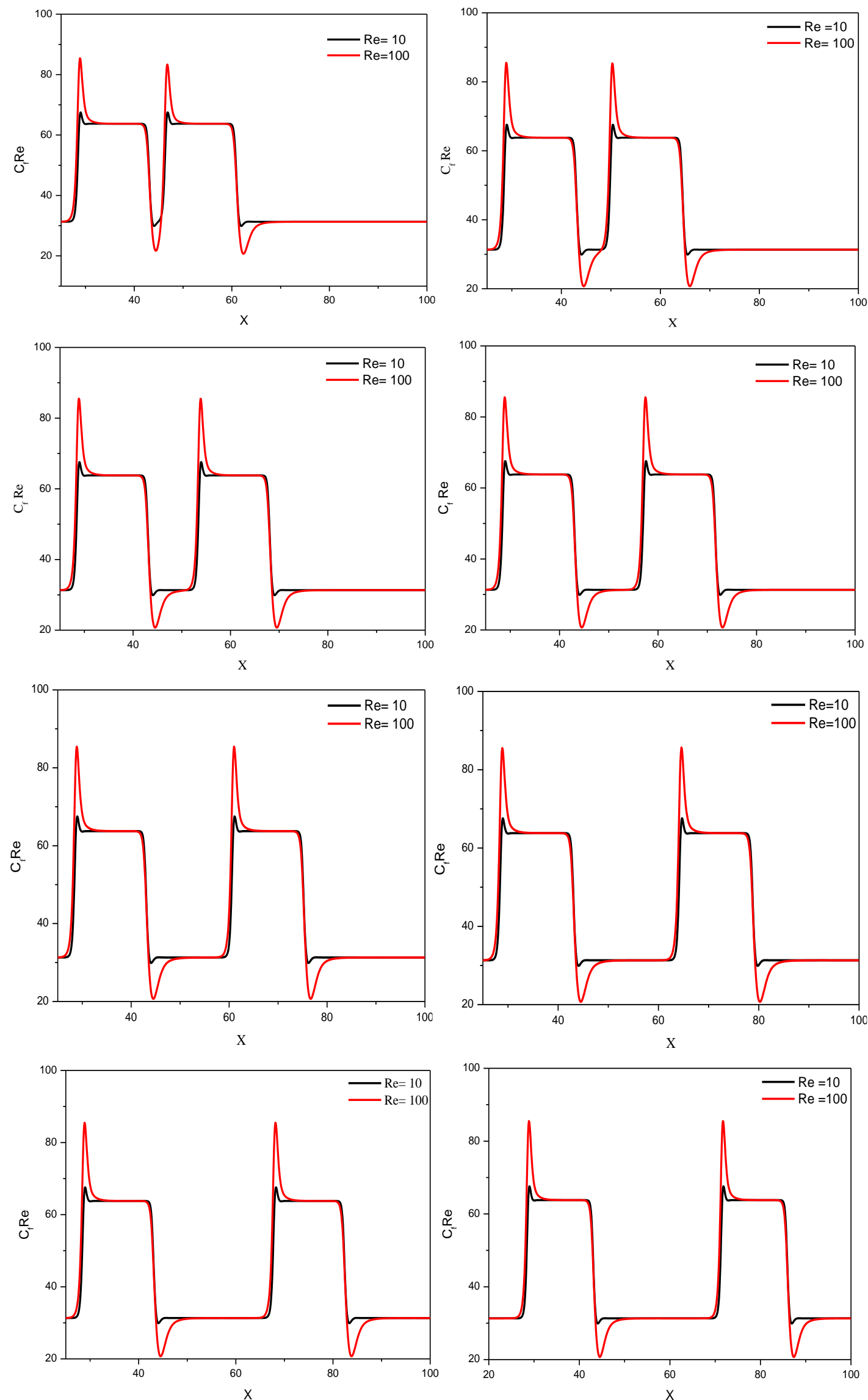

Figure 13. Poiseuille number profiles along the dimensionless length of the microchannel upper wall for $\varphi=4 \%$ and for different cases. 


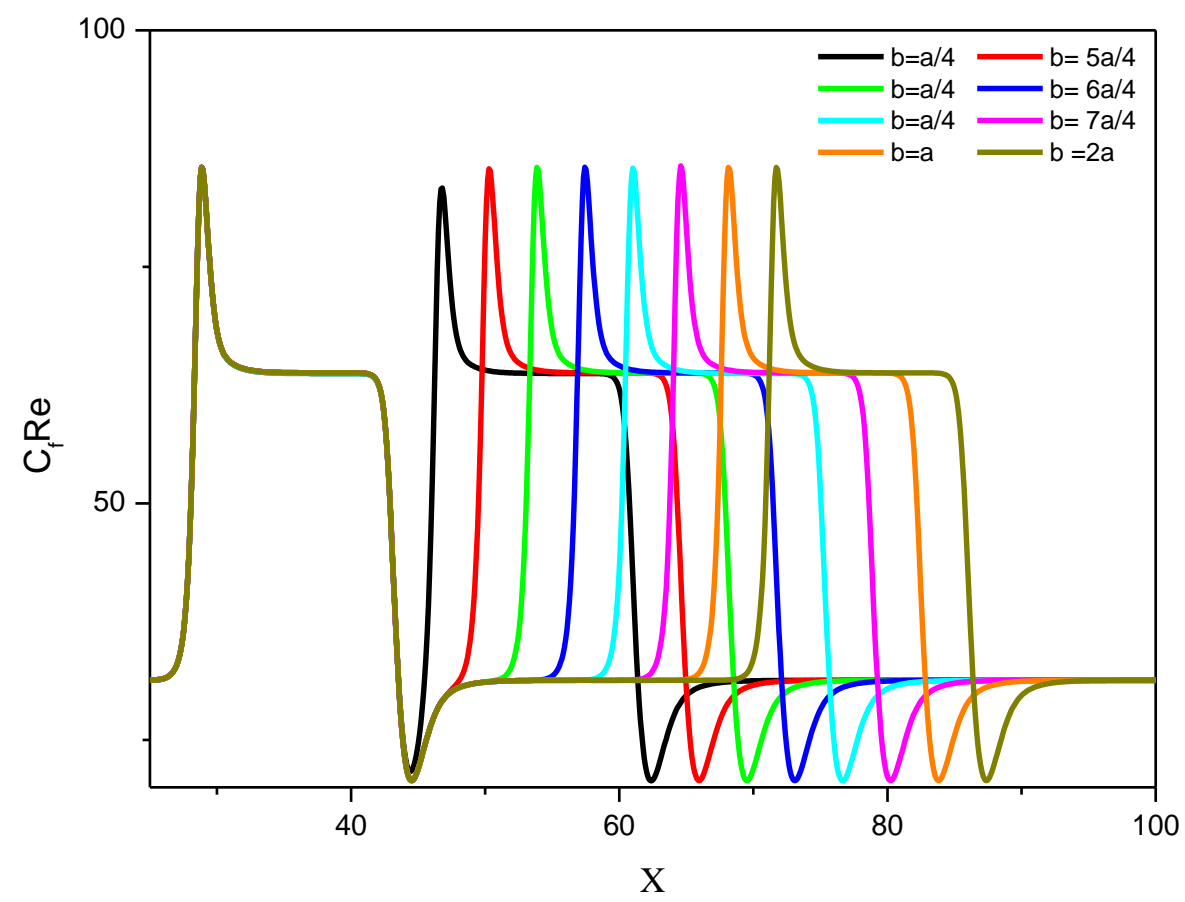

Figure 14. Effect of spacing on Poiseuille number profiles for $\varphi=4 \%$ and $\operatorname{Re}=100$.

Figure 12 represents the Poiseuille number along the upper wall of micro-channel for different volume frcation and at $\mathrm{Re}=10$. It is found that the poiseuilles number increases as nanaoparticle cencentration increases.Fig. 13 depicts the profile along the upper wall of microchannel for $\phi=4 \%$. It shows that Poiseuille number values increase along the ribs surface which it is related to the velocity increasing in this areas. The Poiseuille number in the ribs areas was greater for $\mathrm{Re}=100$ then for $\mathrm{Re}=10$. Fig 14 demonstrates the effect of incerasing distance betwenn ribs (b) on the poiseuille number. It is showed that increasing $b$ leads to decrease the Poiseuille number in the areas between ribs .

\section{CONCLUSION}

Numerical investigation of laminar forced convection heat transfer in a rectangular ribbed microchannel was carried out. The central part of the lower wall has been maintained at constant temperature.The effect of several parameters such as different nanoparticles volume fraction in the range of (0-4\%), Reynolds number (10-100) and spacing between ribs was examined. The finite volume method has been used to solve the governing equations. The results can be synthesized as follow: increasing nanopaticles volume fraction and Reynolds number lead to increase the Nusselt and the Poiseuille number. Also, adding ribs in microchannel wall improves the heat transfer rate. Whereas, increasing the spacing between ribs reduces Nusselt number.

\section{NOMENCLATURE}

a Length of ribs, $m$

A Area, $\mathrm{m}^{2}$

b Distance between ribs

Bf Based fluid

Cp Specific heat of fluid

Cf Specific heat of fluid

$\mathrm{C}_{\mathrm{f}} \mathrm{Re} \quad$ Poiseuille number

Cp Heat capacity, J/kgK

$\mathrm{D}_{\mathrm{h}} \quad$ hydraulic diameter

h ribs heigt

$\mathrm{H} \quad$ Height of microchannel

K Thermal conductivity 


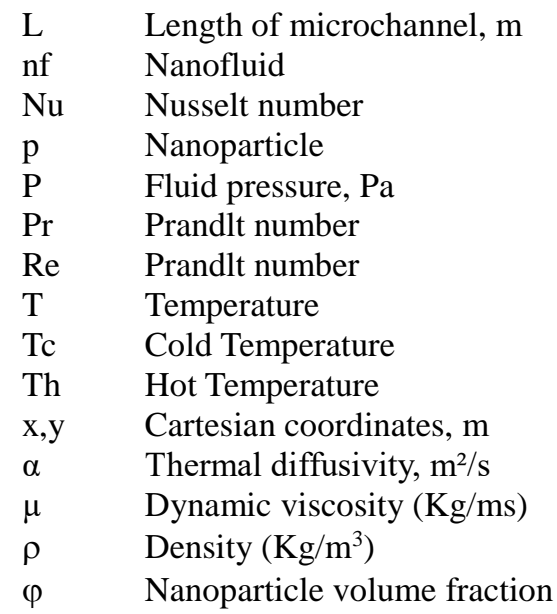

\section{REFERENCES}

[1] Bergles, A. E. (1988). Some perspectives on enhanced heat transfer-second-generation heat transfer technology. Journal of Heat Transfer, 110(4b), 1082-1096.

[2] Tuckerman, D. B., \& Pease, R. F. W. (1981). High-performance heat sinking for VLSI. IEEE Electron device letters, 2(5), 126-129.

[3] Choi, S. U. S., \& Estman, J. A. (1995). Enhancing thermal conductivity of fluids with nanoparticles. ASMEPublications-Fed, 231, 99-106.

[4] Yoo, D. H., Hong, K. S., \& Yang, H. S. (2007). Study of thermal conductivity of nanofluids for the application of heat transfer fluids. Thermochimica Acta, 455(1-2), 66-69.

[5] Choi, S. U. S., Zhang, Z. G., Yu, W., Lockwood, F. E., \& Grulke, E. A. (2001). Anomalous thermal conductivity enhancement in nanotube suspensions. Applied physics letters, 79(14), 2252-2254.

[6] Hamilton, R. L., \& Crosser, O. K. (1962). Thermal conductivity of heterogeneous two-component systems. Industrial \& Engineering Chemistry Fundamentals, 1(3), 187-191.

[7] Murshed, S. M. S., Leong, K. C., \& Yang, C. (2005). Enhanced thermal conductivity of TiO2-water based nanofluids. International Journal of thermal sciences, 44(4), 367-373.

[8] Ansari, D., Husain, A., \& Kim, K. Y. (2010). Multiobjective optimization of a grooved micro-channel heat sink. IEEE transactions on components and packaging technologies, 33(4), 767-776.

[9] Ghale, Z. Y., Haghshenasfard, M., \& Esfahany, M. N. (2015). Investigation of nanofluids heat transfer in a ribbed microchannel heat sink using single-phase and multiphase CFD models. International Communications in Heat and Mass Transfer, 68, 122-129.

[10] Huh, M., Liu, Y. H., \& Han, J. C. (2009). Effect of rib height on heat transfer in a two pass rectangular channel $(\mathrm{AR}=1: 4)$ with a sharp entrance at high rotation numbers. International Journal of Heat and Mass Transfer, 52(19-20), 4635-4649.

[11] Karimipour, A., Alipour, H., Akbari, O. A., Semiromi, D. T., \& Esfe, M. H. (2015). Studying the effect of indentation on flow parameters and slow heat transfer of water-silver nano-fluid with varying volume fraction in a rectangular two-dimensional micro channel. Indian Journal of Science and Technology, 8(15).

[12] Akbari, O. A., Toghraie, D., Karimipour, A., Safaei, M. R., Goodarzi, M., Alipour, H., \& Dahari, M. (2016). Investigation of rib's height effect on heat transfer and flow parameters of laminar water-Al2O3 nanofluid in a rib-microchannel. Applied Mathematics and Computation, 290, 135-153.

[13] Al-Shamani, A. N., Sopian, K., Mohammed, H. A., Mat, S., Ruslan, M. H., \& Abed, A. M. (2015). Enhancement heat transfer characteristics in the channel with Trapezoidal rib-groove using nanofluids. Case Studies in Thermal Engineering, 5, 48-58.

[14] Manca, O., Nardini, S., \& Ricci, D. (2012). A numerical study of nanofluid forced convection in ribbed channels. Applied Thermal Engineering, 37, 280-292.

[15] Wang, L., \& Sundén, B. (2007). Experimental investigation of local heat transfer in a square duct with various-shaped ribs. Heat and Mass Transfer, 43(8), 759.

[16] Andreozzi, A., Manca, O., Nardini, S., \& Ricci, D. (2016). Forced convection enhancement in channels with transversal ribs and nanofluids. Applied Thermal Engineering, 98, 1044-1053.

[17] Maiga, S. E. B., Palm, S. J., Nguyen, C. T., Roy, G., \& Galanis, N. (2005). Heat transfer enhancement by using nanofluids in forced convection flows. International journal of heat and fluid flow, 26(4), 530-546.

[18] El Bécaye Maïga, S., Tam Nguyen, C., Galanis, N., Roy, G., Maré, T., \& Coqueux, M. (2006). Heat transfer enhancement in turbulent tube flow using $\mathrm{Al} 2 \mathrm{O} 3$ nanoparticle suspension. International Journal of Numerical Methods for Heat \& Fluid Flow, 16(3), 275-292. 
[19] Xuan, Y., \& Roetzel, W. (2000). Conceptions for heat transfer correlation of nanofluids. International Journal of heat and Mass transfer, 43(19), 3701-3707.

[20] Mintsa, H. A., Roy, G., Nguyen, C. T., \& Doucet, D. (2009). New temperature dependent thermal conductivity data for water-based nanofluids. International Journal of Thermal Sciences, 48(2), 363-371.

[21] Kandlikar, S., Garimella, S., Li, D., Colin, S., \& King, M. R. (2005). Heat transfer and fluid flow in minichannels and microchannels. elsevier. 